\title{
REVIEW
}

\section{Coronavirus covid-2019: Is this really an invisible enemy or a warning to humanity?}

\author{
Modeste Kameni Nematchoua ${ }^{1,2}$
}

\begin{abstract}
With more than 8 million confirmed cases, and more than four hundred and thirty thousand deaths declared to date worldwide, the Coronavirus pandemic (COVID-19) is recognized as one of the deadliest pandemics that the humanity has known in recent years. So far, although this disease has been declared as an invisible enemy by many scientists and politicians, its origin remains without explanation more reliable and reassuring by the scientific community. As a result, the following questions remain without explanation. Can this pandemic be considered a warning to humanity? When will the end of this pandemic come? Has it become a matter of industrial lobbies as said some people? The main purpose of this research is to analyse some research related to the recently published Coronavirus (COVID-19) pandemic in order to offer some answers to these questions. It emerges from this analysis that the most reliable solution to overcome this pandemic is to disclose the results of the progress of this pandemic by the scientific, and to multiply public awareness campaigns.
\end{abstract}

Keywords: coronavirus, warning, disease, humanity

\section{Background}

Human beings believe dominate the world through their knowledge. However, for centuries the origin of certain pandemics and natural disasters has remained without reliable explanation by the scientific community. During these decades, disasters have become more serious worldwide. Indeed, earthquakes, plagues, famines, floods, droughts, and insect invasions occur frequently and spread all over the world. The following Table 1, shows some natural disasters recorded since $11^{\text {th }}$ century.

\section{COVID-19 recognized as the novel pan- demic}

\subsection{Origin}

The new SARS-Cov2 coronavirus that causes Covid19 disease was first discovered in China, in the city of Wuhan. Coronaviruses are a family of viruses that mainly

\footnotetext{
Received: July 1, 2020 Accepted: August 31, 2020 Published: September 2, 2020

* Correspondence to: Modeste Kameni Nematchoua, Beneficiary of an AXA Research Fund postdoctoral grant, Research LeadersFellowships, AXA SA 25 avenue Matignon, Paris 75008, France; Email: kameni.modeste@yahoo.fr

${ }^{1}$ Beneficiary of an AXA Research Fund postdoctoral grant, Research LeadersFellowships, AXA SA 25 avenue Matignon, Paris 75008 , France

${ }^{2}$ LEMA, UEE, ArGenCo Department, University of Liège, Liège 4000, Belgium

Citation: Nematchoua MK. Coronavirus covid-2019: Is this really an invisible enemy or a warning to humanity?. Health Environ, 2020, 1(1): 48-61.

Copyright: $\odot 2020$ Modeste Kameni Nematchoua. This is an open access article distributed under the terms of the Creative Commons Attribution License, which permits unrestricted use, distribution, and reproduction in any medium, provided the original author and source are credited.
}

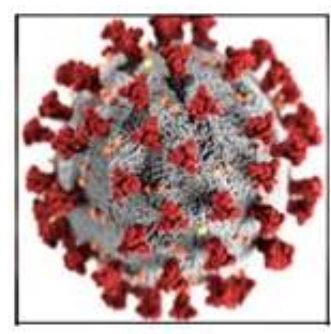

Figure 1. Imagen of Coronavirus

affect animals. Some infect humans and most often cause colds and mild influenza-like illness.

Some scientists say (that) may be coronaviruses come from bats. Indeed, the bat is probably the animal reservoir of this virus.

In contrast, some scientists believe that it is a virus that escaped from one of the Chinese laboratories located in Wuhan. The political quarrels, rivalry, competition, and pride of certain governments prevent until now scientists from determining the true cause of this disease.

\subsection{History}

The very first case reported from COVID 19, was a 55-year-old patient, who fell ill on November 17, 2019 in $\mathrm{China}^{[2]}$. A month later, on December 15, the number of cases reported was 27. On December 20, it increased to 60 , including several people who worked at the Huanan seafood market ${ }^{[3]}$. On December 21, the doctors realized that they were in the presence of a new respiratory 
Table 1. Some disasters

\begin{tabular}{|c|c|c|c|c|}
\hline Type & Number of deaths & Event & Location & Time (period) \\
\hline Epidemics & 250000000 & Black Plague & world & 11 th to 17 th century \\
\hline Epidemics & 300000000 & Smallpox & world & From 1900 to $1977^{[1]}$ \\
\hline Famines & 29000000 & Great famine in China & China & $1958-1961$ \\
\hline Flood & 2072500 & Floods & China & 1931 \\
\hline Earthquake & 830000 & Shaanxi earthquake & China & January 23,1556 \\
\hline cyclones & 362000 & Bhola cyclone & Bangladesh & November, 1970 \\
\hline Tsunami & 225500 & Indian Ocean earthquake and tsunami & Indonesia, Sri Lanka, India and Thailand & December, 2004 \\
\hline Volcanic eruption & 78209 & Krakatoa eruption & Krakatoa, Indonesia & August 27, 1883 \\
\hline Drought & 70000 & European heat wave & Europe & 2003 \\
\hline Avalanche & 20000 & The avalanche of Mount Huascarán & Peru & 1970 \\
\hline Hurricane & 15100 & Vargas tragedy & Venezuela & 1999 \\
\hline Lightning & 4000 & Palace of the Grand Master Explosion, Rhodes & Greece & 1856 \\
\hline Blizzard & 4000 & Blizzard from 1972 in Iran & Iran & 1972 \\
\hline Fire & 1850 & Peshtigo Fire & Wisconsin, United States & October 8,1871 \\
\hline Limnic rash & 1744 & Nyos Lake & Cameroon & 1986 \\
\hline Tornado & 1300 & Daulatpur - Saturia Tornado & Manikganj, Bangladesh & 1989 \\
\hline Earthquake & 22000 & earth quake of magnitude 7 & Haiti & January 12,2010 \\
\hline Earthquake & 723 & earth quake of magnitude 8.8 & Chile & February 27, 2010 \\
\hline Drought & - & Important drought & 5 provinces in China & March, 2010 \\
\hline Mud flow & 1239 & Huge mudslide & Zhouqu in China & August 07,2010 \\
\hline Flood & 12 & flood & Australia & January 12,2011 \\
\hline Earthquake & 18500 & tsunami & Japan & Mars 11,2011 \\
\hline Drought & - & Heat wave & Germany and Swiss & April, 2011 \\
\hline Volcanic eruption & - & Volcanic eruption & Chile & June 4, 2011 \\
\hline Flood & 427 & flood & Thailand & July-October, 2011 \\
\hline Famines & More than 10000 & Huge drought & East- Africa & July-August, 2011 \\
\hline Drought & - & drought record & United States & 2012 \\
\hline Flood & 37 & torrential rain & Pekin-China & July,2012 \\
\hline Hurricane & 210 & Hurricane Sandy & United States & October, 2012 \\
\hline Plague & - & Grasshopper invasion & Israel & March, 2013 \\
\hline Plague & - & H7L9 Avian Flu & China & March, 2013 \\
\hline Flood & 5000 & flood & India & June, 2013 \\
\hline Wind & 1 & Huge wind & California-United States & August 25, 2013 \\
\hline Blizzard & 2 & Blizzard & Middle east & December, 2013 \\
\hline Avalanche & - & Avalanche & North of America & January 2, 2014 \\
\hline Earthquake & 9000 & Earthquake of magnitude 7.8 & Nepal & April, 2015 \\
\hline Flood & 12 & flood & Georgia & June, 2015 \\
\hline Earthquake & 676 & Earthquake of magnitude 6.8 & India & January, 2016 \\
\hline Earthquake & 700 & earthquake & Equator & April, 2016 \\
\hline Earthquake & 369 & Earthquake & Mexico & September, 2017 \\
\hline Flood & 100 & torrential rain & Japan & July, 2018 \\
\hline Tsunami & 2000 & Earthquake and tsunami & Indonesia & September 28,2018 \\
\hline Pandemic & More than 500000 & Coronavirus & world & From December, 2019 \\
\hline
\end{tabular}

pathogen. On December 31, 2019, a third country officially informed the world Health Organization (WHO) of the occurrence of numerous cases of pneumonia of unknown origin in the city of Wuhan. On January 6, the United States Centres for Disease Control and Prevention (US CDC) communicated about the risks of an epidemic. On January 7, 2020, the Chinese authorities confirmed that it was indeed a new virus from the coronavirus family, temporarily baptized "2019-nCoV", and reported around sixty victims. Wuhan coronavirus, known internationally as "2019 novel Coronavirus" abbreviated 2019-nCov, sometimes called "Wuhan seafood market pneumonia virus", is the coronavirus that causes the pneumonia epidemic from Wuhan, provisional name which was taken up by the Institute Pasteur, because it is up to the World Health Organization (WHO) to give its final name to this new pathology. On January 9, 2020, the WHO launched an international alert. On January 21 , WHO released its first daily report on the epidemic . On January 23 , WHO announced that the disease is communicable between humans . On January 24, the WHO indicated that the modes of transmission of the disease are probably the same as for other coronaviruses: direct contact via the respiratory droplets ejected during speech (postillons), cough and sneezing or via objects contaminated by these droplets. On January 26, the National Health Commission of China announced that the new virus has an incubation period of up to two weeks, and most importantly, contagion is possible during the incubation period. Therefore, if it is not subject to a systematic and early detection policy, it is likely to spread with exponential growth. On January 30, WHO declared the epidemic a public health emergency of international concern (USPPI). Some people mentioned "disease X", the name given in 2018 by the WHO to a disease likely to cause international danger. On February 11 , WHO officially named the disease: "Coronavirus 
disease 2019 (COVID-19). The virus was also named: "severe acute respiratory syndrome coronavirus 2 (SARSCoV-2)". On February 27, WHO published a guide on preventive measures to curb the epidemic. On March 11, the Director General of WHO described COVID-19 as a pandemic, noting that it was the first time that a pandemic had been caused by a coronavirus. The pangolin as shown in Figure 2, is one of the animals suspected of having transmitted the virus to humans, via a market in Wuhan.

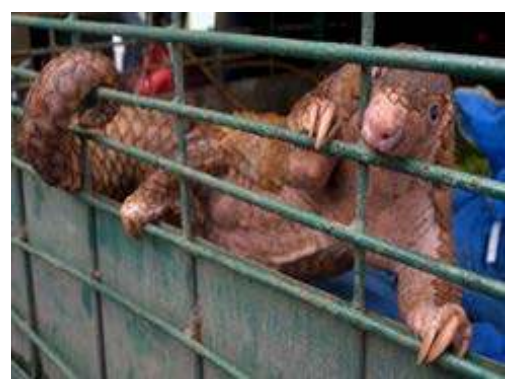

Figure 2. An animal suspected of having transmitted the virus to humans

\subsection{Transmission}

According to world Health Organization (WHO) ${ }^{[4]}$, COVID-19 is spread when people are in close contact via small droplets emitted during conversation, sneezing, or coughing. According to Disease Control and Prevention $(\mathrm{CDC})^{[5]}$, contaminated droplets spread by infected people are then inhaled into the lungs or deposited on the face of others to cause a new infection. These very heavy droplets, usually fall on surfaces without being spread far in the air(Figure 3). Thus, transmission of the virus can be done with no physical symptoms. The frequency with which this occurs is not very clear. An estimation of the number of asymptomatic infected people is around $40 \%$.

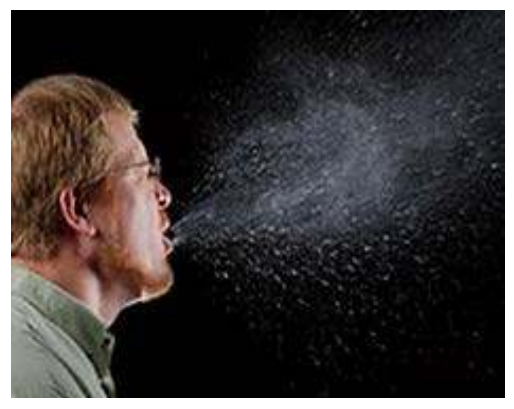

Figure 3. Coronavirus spread in space by a patient

The vulnerability and transmission rate is very high for people with mild or non-specific symptoms. The first symptoms of the disease appear after two days or more, these depend on the ability of the patient's body to cope with this disease. All patients are strongly affected by this disease for seven to twelve days in moderate cases, and on average two weeks in more severe cases ${ }^{[4]}$.

When contaminated droplets emitted into space by contaminated people fall on soils, this surface remains infected. If suddenly, healthy people touch these affected surfaces, then their eyes, nose, or mouth with unwashed hands ${ }^{[5]}$. They immediately get this disease. In contaminated surfaces, the amount of active virus decreases over time until it can no longer cause an infection. Studies have shown that saliva and sputum carry large amounts of the virus ${ }^{[3-5]}$. Although this disease is not recognized as a sexually transmitted disease, the fact remains that kissing, intimate contact and the faecal-oral tract are suspected of transmitting the virus ${ }^{[6]}$.

It is not known how much virus on surfaces is needed to cause infection via this method, but it can be detected for up to four hours on copper, up to one day on cardboard and up to three days on plastic (polypropylene) and stainless steel $^{[4,7,8]}$. Surfaces are easily decontaminated with household disinfectants that kill the virus outside the human body or on the hands ${ }^{[4]}$. Disinfectants or bleach are not a treatment for COVID - 19 and cause health problems when used improperly, such as when used inside the human body ${ }^{[8]}$. Numerous researches claim that the various symptoms of this disease have so far not been fully understood ${ }^{[7,8]}$.

Coronavirus is easily spread between people - faster than the flu, but less than measles ${ }^{[4]}$. Estimates of the number of people infected with someone with COVID-19 (R0) have varied considerably. WHO's initial estimates of R0 were 1.4-2.5 (mean 1.95), but a more recent review found that baseline R0 (without controls) was higher than 3,28 and the median R0 at 2.79 .

\subsection{Symptoms}

Fever is known as the most common symptom. However, some people who have other health problems and older people suffer from fever later in the disease ${ }^{[10,11]}$.

A lack of fever does not verify that a person is not a carrier of the disease. Other symptoms developed by carriers of this virus are coughing, loss of appetite, fatigue, shortness of breath, sputum production and muscle and joint pain ${ }^{[12]}$. Symptoms such as vomiting, nausea, and diarrhea were seen in patients to different degrees ${ }^{[13,14]}$. Less common symptoms include runny nose, sneezing, sore throat and skin lesions, among others ${ }^{[15]}$. Other cases seen in several countries initially presented with palpitation and chest tightness ${ }^{[16]}$. In addition, a decrease in smell or taste disturbances may occur ${ }^{[17]}$. As with most infections, the average incubation period for COVID 19 (when a person first is infected and when they de- 
velop symptoms) is five to six days, but it usually varies from one to 14 days, around $10 \%$ of cases exceeding this period $^{[18,19]}$. It is noted that a minority of cases does not develop any perceptible symptom at a given time ${ }^{[20]}$. These asymptomatic carriers tend not to be tested, and their role in transmission is not yet fully understood ${ }^{[21]}$. However, preliminary evidence suggests that they may be contributing to the spread of the disease ${ }^{[22]}$. Figure 4 shows some symptoms of coronavirus.

\begin{tabular}{|r|r|}
\hline $\begin{array}{r}\text { Common symptoms: } \\
\text { Fever: } 83-99 \%\end{array}$ & $\begin{array}{c}\text { In severe disease: } \\
\text { Difficulty waking }\end{array}$ \\
Loss of Appetite: $40-84 \%$ \\
Fatigue: $44-70 \%$
\end{tabular}

Figure 4. Symptoms of Coronavirus disease 2019

\subsection{Review}

Scopus website, 162 documents have been published since January 2020 up to now analysing coronavirus, which constituted of 82 articles, 34 letters, 18 editorials, 16 reviews, and 10 notes. All those articles were published in various subject areas such as medicine (135documents); immunology and microbiology (16 documents); Biochemistry, Genetics and Molecular Biology (15 documents); Pharmacology, Toxicology and Pharmaceutics (8); and Psychology (8).

Huang et al. ${ }^{[23]}$ carried out clinical, epidemiological, radiological, biological studies, as well as the treatment of a group of coronavirus patients in Wuhan, China. All the data collected were obtained using the WHO standardized data collection. Patients and their families were examined to verify epidemiological data and symptoms. An analysis and comparison were made between the results of examinations of patients admitted to intensive care and those who were not; 41 patients were identified as laboratory-confirmed Corunavirus infected and hospitalized on January 2. These patients consisted of $73 \%$ men; the $32 \%$ of these patients suffered from an underlying disease, such as hypertension (15\%), diabetes $(20 \%)$, and cardiovascular disease (6\%). Of these patients, $66 \%$ were exposed to the Huanan seafood market. As common symptoms, it was noticed in the patients that $98 \%$ had a fever, $76 \%$ had a cough, and the $44 \%$ showed signs of fatigue. Furthermore, it was noted that $8 \%$ of patients had a production of headache; haemoptysis (5\%); sputum production (28\%); dyspnoea (55\%). It was interesting to note that all of these patients had pneumonia with abnormal chest CT results. The $29 \%$ of patients had complications manifested by acute respiratory distress, $15 \%$ by RN Aaemia, and $12 \%$ with acute cardiac injury. In total, $15 \%$ died.

In April 2020, research carried out, by Peter Byass ${ }^{[24]}$, in the purpose of studying the spread of COVID-19 in China, resulting from the link between identified cases and ecological factors, such as temperature, population density, precipitation, and solar radiation. The analysis was based on 18,069 patients identified between January and February. Among the 15,539 cells in the grid, only $559(3.6 \%)$ had at least one case, and these were used in the construction of a Poisson regression model. The finding of this research showed that meteorological conditions can have a significant effect under the propagation and understanding of COVID-19. Fei Zhou et al. ${ }^{[25]}$ studied the clinical course of COVID-19 disease, viral excretion, as well as the risk factors for mortality. This research was based on all hospitalized patients over 18 years of age with COVID-19, identified at Jinyintan and Wuhan hospitals in China, who were released and died on January 31,2020 . The clinical, laboratory, demographic, treatment, and sampling data for the detection of viral RNA were provided by the medical records patients. The risk factors associated with hospital deaths were assessed using logistic regression methods. This study evaluated the cases of 191 patients, with 137 cures and 54 who died in the hospital. Examinations showed that $48 \%$ of these patients showed signs of comorbidity; such as hypertension (30\%), diabetes (19\%). A large increase in in-hospital deaths of patients with advanced age was observed. Findings showed that potential risk factors for advanced age with a high Sequential Organ Failure Assessment score and a d-dimer greater than $1 \mu \mathrm{g} / \mathrm{mL}$ may help clinicians detect patients with poor prognosis at an early stage. According to Torres and Siche ${ }^{[26]}$, COVID 19 is wreaking havoc, in fact, in the short and medium term, rich and poor, professional and non-professional, regardless of race, religion, sex or age, will undoubtedly suffer from a mental disorder associated with COVID-19. Governments will not only face economic problems, but may also face a bigger problem, the mental health of their people. In Addition, Lascaux et al. ${ }^{[27]}$ had made a statistical analysis of the evolution of COVID-19 infection in Puglia, Sardinia, Sicily which are cities distributed in three Italian regions, with a look under different betathalassemic prevalences, in the aim to verify the existing link. The findings explained that the prevalence of the beta thalassemic heterozygous population is correlated with immunity to COVID-19, by regression. 
Nowadays, there is no effective vaccine to combat this coronavirus pandemic. Indeed, countermeasures are based on preventing or slowing down person-to-person transmission $^{[28]}$. More specifically, increasing efforts are being made to prevent or reduce transmission to front-line health workers. However, one of the major concerns of the international community is the problem of a shortage in the supply chain of personal disposable and critical protective equipment ${ }^{[28]}$. The studies of Liu et al. ${ }^{[29]}$ aims to explore associations between the number of new cases of coronavirus 2019 and weather factors in 30 provincial capitals of China. The data compiled took into account the number of confirmed people, the ambient temperature, the daytime temperature range, the absolute humidity and the migration scale index for each city studied between January 20 and March 2, 2020. All First, a non-linear regression was used to analyse the link between the number of cases confirmed by COVID-19 and the meteorological factors. Linear models with a negative binomial distribution were fitted to assess the direct effect of weather factors on the number of confirmed cases. Subsequently, a meta-analysis was conducted to quantify the grouped effects. The results showed that Each $1^{\circ} \mathrm{C}$ increase in room temperature and daytime temperature range was linked to the decrease in the number of daily confirmed cases of COVID19. Furthermore, it was found that the patient's vulnerability period was cumulative up to 14 days. According to Vecchio et al. ${ }^{[30]}$, Overall, the Covid19 pandemic has caused considerable damage to major challenges in all countries of the world. The death rate is very high in people with a history of opioid use disorder and addiction. In most countries, a reorganization of the health system has been envisaged to combat the pandemic. The measures recommended to limit the spread of COVID19, such as isolation and social isolation, reduce the mortality percentage and the burden on health and social protection systems. The studies of Merindol et al. ${ }^{[31]}$ showed that rapid and reliable screening for SARS-CoV-2 is necessary to estimate the viral spread and reduce the pandemic we are facing. The direct rRT-PCR method, without RNA extraction using SeeGene AllplexTM 2019nCoV rRT-PCR was analysed. In addition, the effect of the composition of swab storage media on the efficiency of PCR was evaluated. The results showed that the SeeGene and Altona tests had similar efficacy. The study conducted by Moghanibashi ${ }^{[32]}$ aimed to analyse the anxiety rate of the Iranian population during the period of spread of the COVID-19 epidemic. A total of 10,754 participants living in 31 Iranian provinces responded to the questionnaires on March 1 and March 9, 2020, on social networks. The results showed that the level of anxiety was highest among women and the group of ages 21 to 40 . Further- more, the level of anxiety was significant in people who had at least one family member with COVID-19. Michael Peters et al. ${ }^{[33]}$ studied genes for ACE2 and TMPRSS2, and of the intercellular adhesion molecule 1 (rhinovirus receptor as a comparator), which originates from different sputum cells from 330 participants in the research program on asthma. The results showed a high level of ACE2 and TMPRSS2 in men. Diabetes patients and the African-American population justified the monitoring of these asthma subgroups for poor results COVID19. The lowest concentration of ACE2 and TMPRSS2 with the use of ICS qualifies a prospective study of the use of ICS as a predictor of reduced susceptibility to SARS-CoV-2 infection and morbidity from COVID19 reduced. The objective of the research conducted by Wei-cai Dai et $a l .{ }^{[34]}$ were compared data from images of pulmonary CT scan of certain patients with COVID-19 in China, and other known lung diseases. The results showed that, unlike NAAT of SARS-CoV-2, which limit detections and often show false negative results, chest CT quickly detects lung lesions and diagnoses imaging at the start. Other important studies related COVID19 were detailed in the literature ${ }^{[35-40]}$.

\section{Coronavirus cases in the world}

Figure 5 shows the evolution of coronavirus since December 2019 up to June 2020. The global confirmed cases showed are 6271,577 (Figure 5a); the global death cases are 375,683 and global recovered cases are 2697,873.

These results show the death rate has reached the $5.99 \%$ this day in the world. Figure 6 gives in details the number of cases of COVID-19 evaluated by the Center for Systems Science and Engineering (CSSE) at Johns Hopkins University (JHU).

Figure 7 shows recent data published by European Centre for Disease Prevention and Control (ECDC).

The rate of people infected is increasing in some countries in Africa. For example, on June 09, 2020, 196570 cases in all the Africa's countries; the five countries reporting most cases are South Africa (50 879), Egypt (35 444), Nigeria (12 801), Algeria (10 265) and Ghana (9 910). Number of people deaths in this continent 5346 ; the five countries reporting most deaths are Egypt (1 271), South Africa (1 080), Algeria (715), Sudan (372) and Nigeria (361).

Europe: 2084509 cases; the five countries reporting most cases are Russia (476 658), United Kingdom (287 399), Spain (241 717), Italy (235 278) and Germany (184 543).Europe: 179385 deaths; the five countries reporting most deaths are United Kingdom (40 597), Italy (33 964), France (29 209), Spain (27 136) and Belgium (9 609). 


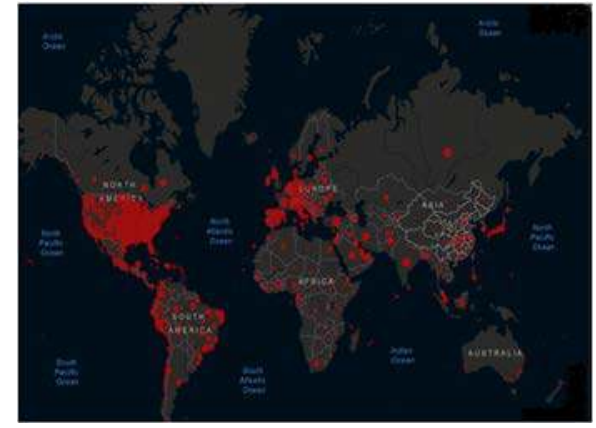

Figure 5a. Cumulative confirmed cases up to 06/02/2020 in the world of COVID-19 given by Centre for Systems Science and Engineering (CSSE) at Johns Hopkins University (JHU)

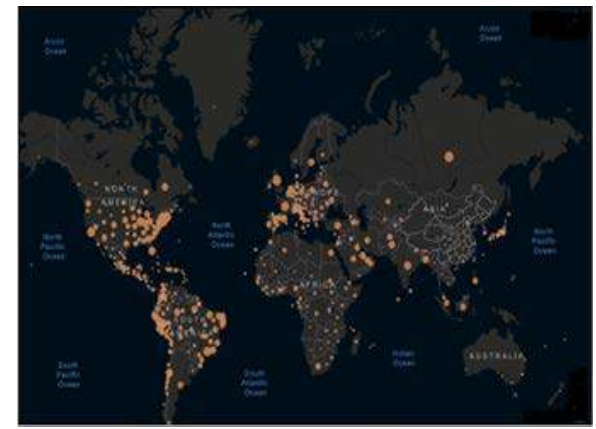

Figure 5b. Active cases on 06/02/2020 in the world of COVID-19 given by Center for Systems Science and Engineering (CSSE) at Johns Hopkins University (JHU)

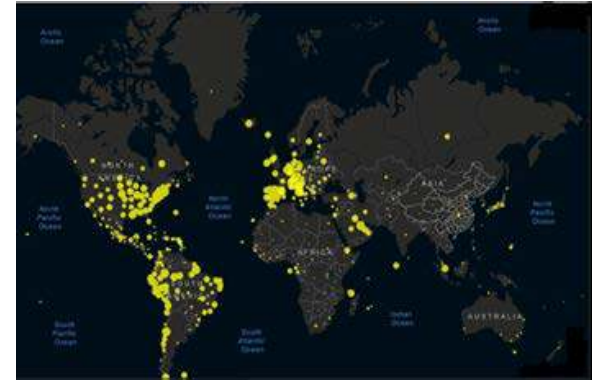

Figure 5c. Incidence rate on 06/02/2020 in the world of COVID-19 given by Center for Systems Science and Engineering (CSSE) at Johns Hopkins University (JHU)

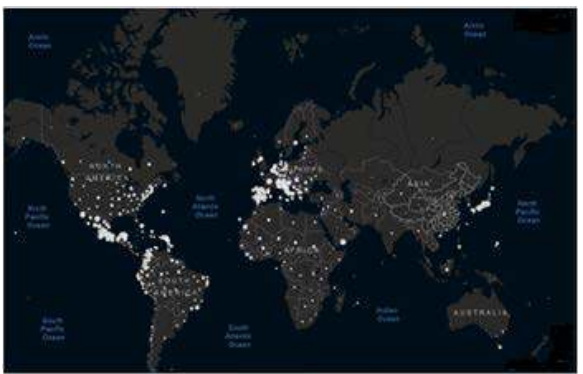

Figure 5d. Case fatality ratio on 06/02/2020 in the world of COVID-19 given by Center for Systems Science and Engineering (CSSE) at Johns Hopkins University (JHU)

Figure 5. The evolution of coronavirus since December 2019 up to June 2020

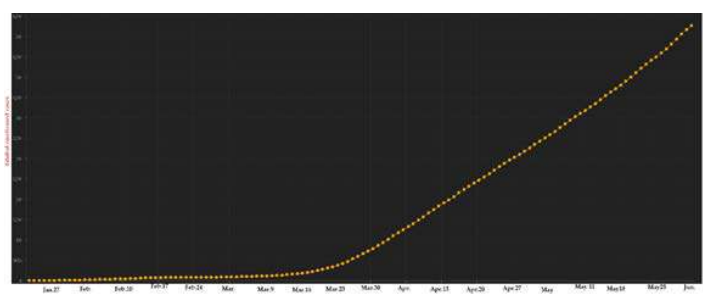

Figure 6. Global confirmed cases from December 2019 to June 2020

America: 3403398 cases; the five countries reporting most cases are United States (1 961 185), Brazil (691 758), Peru (199 696), Chile (138 846) and Mexico (120 102).America: 185311 deaths; the five countries reporting most deaths are United States (111 007), Brazil (36 455), Mexico (14 053), Canada (7 835) and Peru (5 571).

Asia: 1375372 cases; the five countries reporting most cases are India (266 598), Iran (173 832), Turkey (171 121), Pakistan (108 317) and Saudi Arabia (105 283). Asia: 35407 deaths; the five countries reporting most deaths are Iran (8 351), India (7 466), Turkey (4 711), China (4 638) and Pakistan (2 172).

Oceania: 8733 cases; the five countries reporting most cases are Australia (7 265), New Zealand (1 154), Guam (180), French Polynesia (60) and Northern Mariana Islands (28). Oceania: 131 deaths; the four countries reporting deaths are Australia (102), New Zealand (22), Guam (5) and Northern Mariana Islands (2).

Seen that the limited testing and challenges in the attribution of the cause of death means that the number of confirmed deaths may not be an accurate count of the true number of deaths from COVID-19. The 10 countries the most affected by this pandemic are: United States, United Kingdom, Italy, Brazil, France, Spain, Mexico, Belgium, Canada and Iran.

\section{Consequences}

\subsection{Social consequences}

Each new day brings thousands of more Covid-19 deaths around the world. Indeed, according to a last count established by the Center for Systems Science and Engineering (CSSE) at Johns Hopkins University (JHU), in the 188 countries listed, for a total confirmed case estimated around 6273402, the $6 \%$ died. These figures underestimate the real scale of the global health crisis because many deaths outside hospitals are neither tested nor counted, for example, in the United States, where the rules vary from one jurisdiction to another. Containment measures, which affect 4 billion people worldwide, raise fears of a global recession ${ }^{[41]}$. Unemployment has increased considerably since the start of the crisis (more than 22 

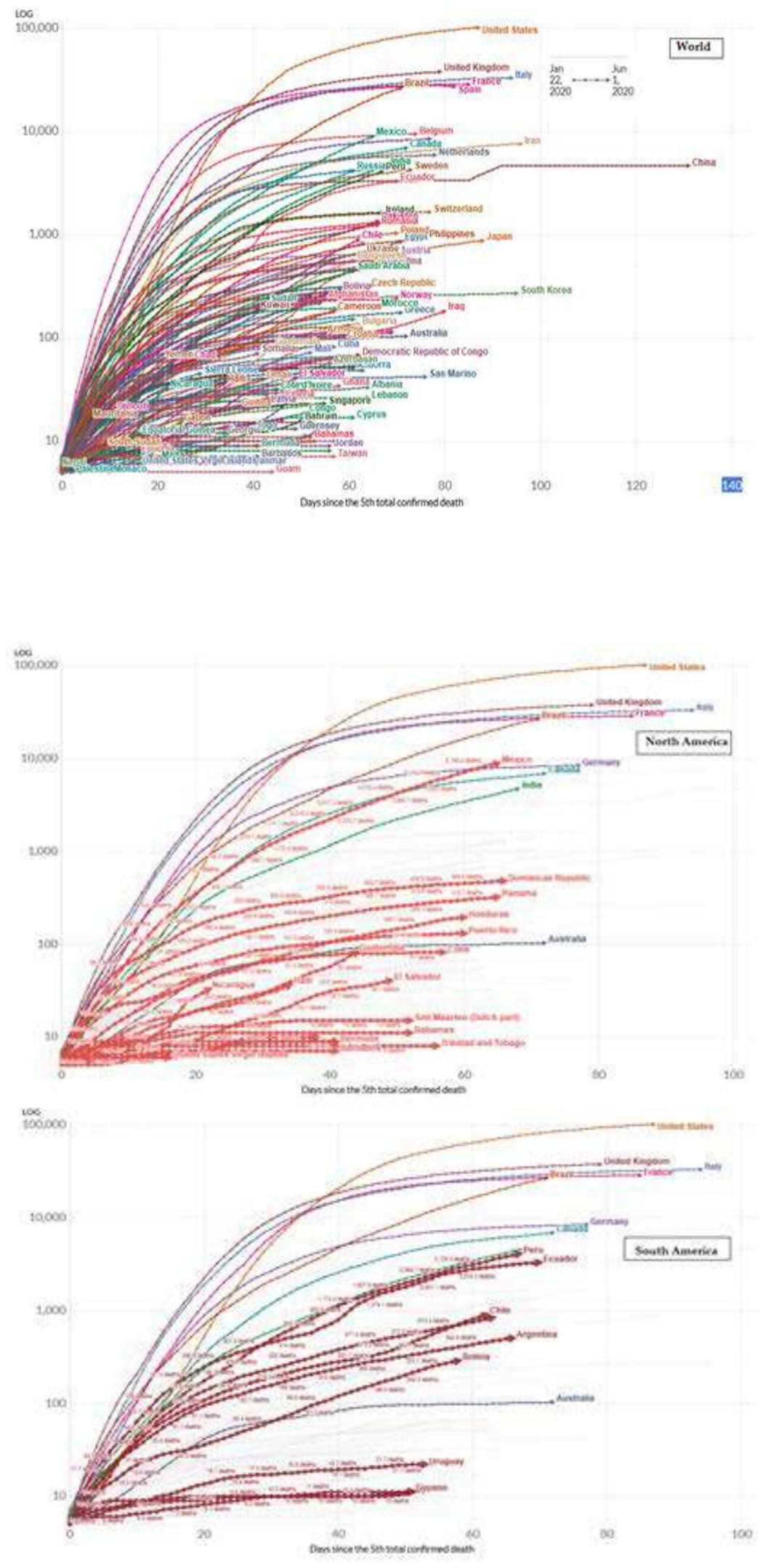

Health and Environment (c) 2020 by Syncsci Publishing. All rights reserved. 

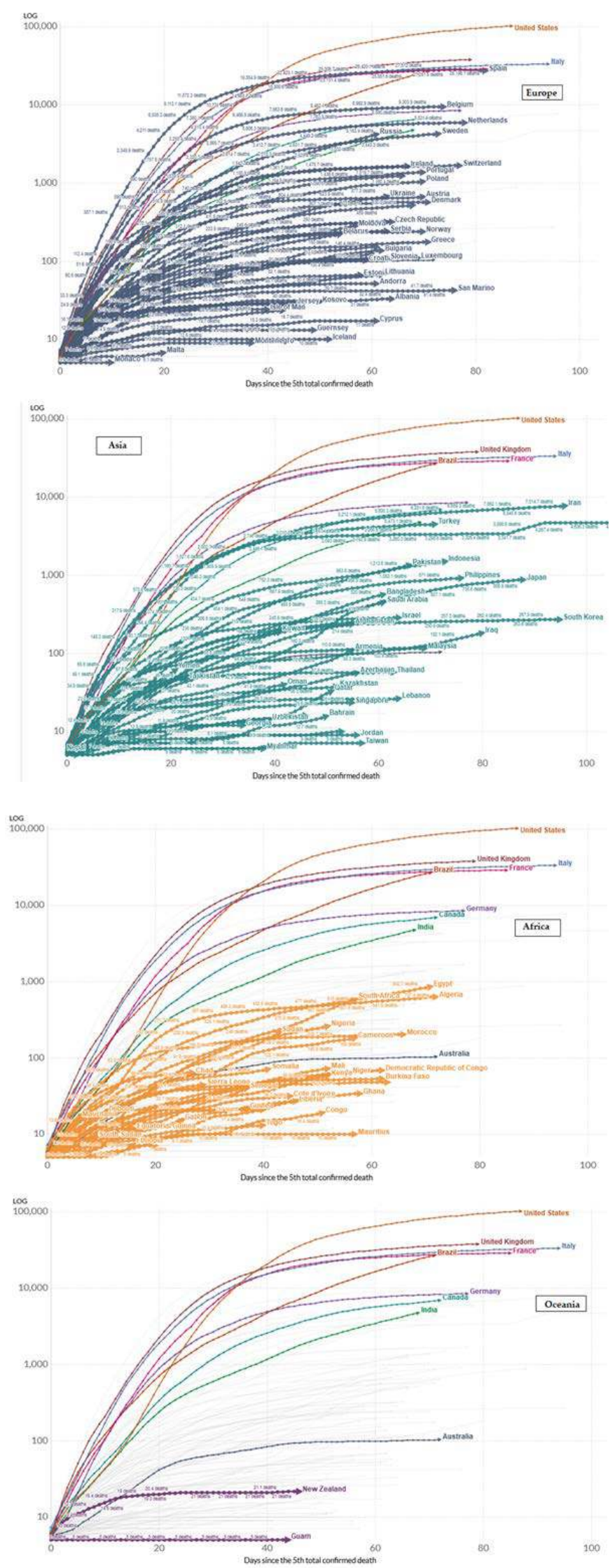

Figure 7. Total confirmed COVID-19 deaths

Health and Environment (c) 2020 by Syncsci Publishing. All rights reserved. 
million in the USA). Food banks are overwhelmed around world... The human cost of confinement is vey high. In addition, that should translate into higher mortality, even after the pandemic is over.

\subsection{Economic consequences}

According to the Managing Director of the IMF, the coronavirus pandemic will cause "the worst economic consequences since the Great Depression" of 1929. Indeed, more than 170 countries will experience a contraction in their per capita income ${ }^{[42]}$.

According to the International Labor Organization (ILO) $)^{[43]}, 1.6$ billion people worldwide, will be affected by this pandemic. In the first month of the crisis alone, the income of informal workers fell by $60 \%$ worldwide. This translates into a fall of $81 \%$ in Africa and the Americas, $21.6 \%$ in Asia-Pacific and 70\% in Europe and Central Asia. Without alternative sources of income, these workers and their families will no longer have a livelihood. Hours of work worldwide decreased in the first quarter by approximately $4.5 \%$ (equivalent to approximately 130 million full-time jobs, based on a 48-hour workweek) from the fourth quarter 2019. In the second quarter, the situation should worsen further due to the extension of the containment measures.

\subsection{Environmental consequences}

During the initial assessment of the 2008 global financial crisis, overall $\mathrm{CO}_{2}$ emissions from the combustion of fossil fuels and the production of cement had decreased by $1.4 \%$, which did not prevent them from increasing by $5,9 \%$ in 2010 .

Today, according to the Center for Research on Energy and Clean Air, methods used to contain the spread of the coronavirus, such as quarantines and travel bans, have resulted in a $25 \%$ reduction in carbon emissions in $\mathrm{China}^{[44,45]}$. In the first month of containment, China produced about 200 million metric tons of carbon dioxide less than over the same period in $2019^{[45]}$. Delhi in India has experienced the most drastic change with a $60 \%$ drop in air pollution.

\section{Comparison}

In this section, we compare the effect of COVID-19 and other diseases. In this sense, Figure 8 shows the case fatality rate by age of COVID 19 . The fatality rate is $2.3 \%$ for all the ages; of $0.2 \%$ between 10 and 39 years old; of $8 \%$ between $70-79$; and $14.8 \%$ for the people over 80 years old.

On this figure, it was seen that the degree of vulnerability increases with age. The age group over 80 is the most

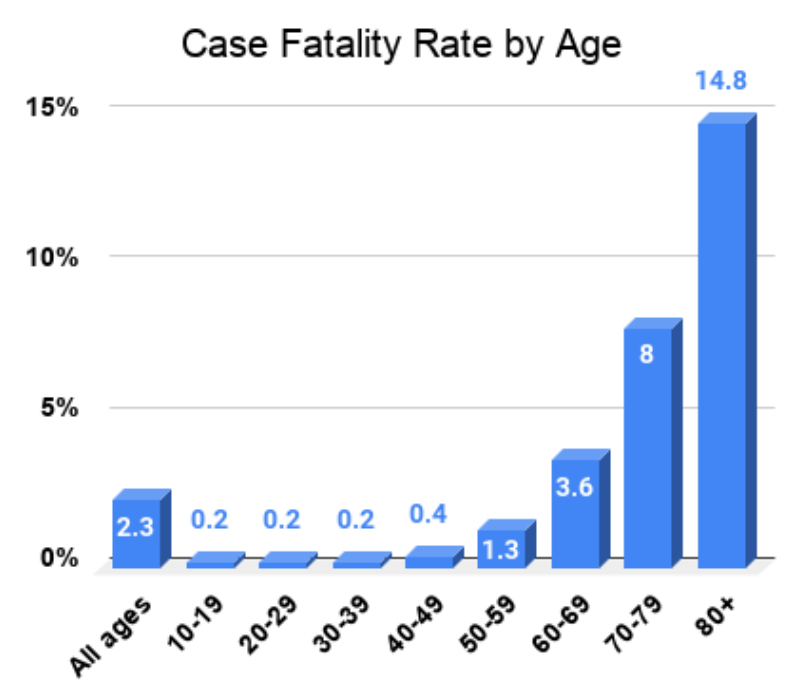

Figure 8. Case fatality rate by age according to Doc James ${ }^{[46]}$

vulnerable. Between 10 and 49 , the mortality rate is from $0.2 \%$ to $0.4 \%$. It is interesting to notice that between 60 and 79 years, the mortality concentration is estimated to be between 3.6 and $8 \%$. (Figure 9)

Among all the diseases studied in this research, it is seen that the mortality rate is $100 \%$ in the case of pneumonia plagues and rabies. One patient of Covid19 can infect in average 3 people, while one patient of Malaria will be infected 17 healthy people.

\section{Treatment}

The COVID-19 pandemic is new and unexpected. This can be destabilizing and cause a feeling of loss of control. It is normal for individuals and communities to experience sadness, stress, confusion, fear and worry during a crisis. Overall, coronavirus infections are diagnosed by health care providers based on the symptoms presented and are confirmed by laboratory tests. The majority of people with mild symptoms will recover on their own. However, if you are concerned about your symptoms, you should closely monitor them and contact your health care provider. At this time, there is no vaccine or treatment yet to cure or prevent this disease. However, research and development activities are underway. The COVID-19 pandemic has prompted a global review of treatments that could be used to treat or prevent disease. The flu shot does not protect you from coronaviruses, but it does protect you from the flu.

For benign forms of Covid-19, treatment is symptomatic, it is recommended:

(1) Take paracetamol for fever and body aches,

(2) To rest, drink lots of water to rehydrate; 


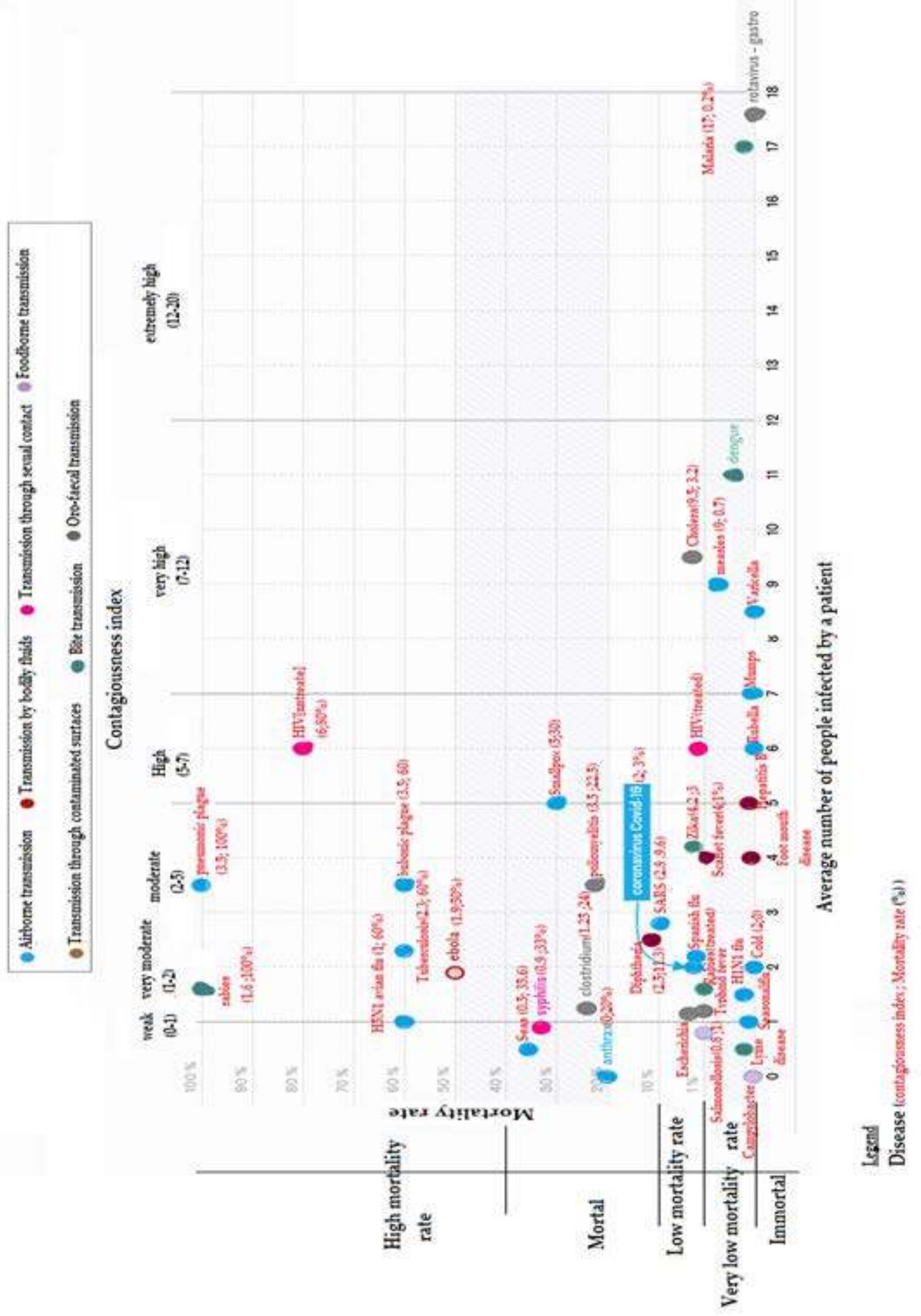

Figure 9. Comparison between Coronavirus and other diseases ${ }^{[41]}$ 
(3) Unclog the nose with physiological saline. Contain yourself and respect hygiene measures to avoid contaminating those around you.

\section{Protection}

Prevention against coronavirus is the same as for influenza and gastroenteritis. It is thus advised:

(1) Wash hands regularly with soap and water, rubbing well between your fingers for at least twenty seconds and rinsing thoroughly;

(2) Favour telework when possible.

(3) Avoid all unnecessary trips and gatherings;

(4) Any trip abroad should be postponed as far as possible.

(5) In places with a high concentration of the population, fix a distance (social distance) of at least $1.5 \mathrm{~m}$ between two people.

(6) Cough or sneeze into your elbow or a disposable handkerchief, to throw in a trashcan.

(7) Avoid kissing or shaking hands to say hello.

Temporary measures such as the closure of nurseries, schools, colleges, high schools and universities are taken to limit the spread of SARS-CoV-2. Schools and airports are reopening is gradually observed in each country according to the reduction in the number of people infected with this disease.

\section{Questions with questionable answers (Qi)}

(Q1): Why in the United States, blacks and the poor people are most affected by Covid-19?

The Washington Post reports that in the state of Michigan, $40 \%$ of deaths from Covid-19 come from the black community, while it represents only $14 \%$ of the population. The high number of deaths in the black community in the United States is largely due to centuries of segregation and discrimination that have relegated a very high proportion of blacks to poor and overcrowded neighborhoods where access to health services is largely insufficient. African-Americans are particularly vulnerable to the coronavirus epidemic because they are more likely to be in low-paid jobs, which cannot be done by telework, and do not offer health insurance or sickness benefits ${ }^{[46]}$.

Several studies show that the poor and marginalized are more prone to respiratory and cardiovascular diseases, cancers, and strokes ${ }^{[4]}$. They are therefore also the most affected by the coronavirus epidemic. In the United States, poverty and ethnicity often go hand in hand ${ }^{[47]}$. Some studied carried out in 2018, showed that $11 \%$ of whites live in households with incomes below the official poverty line, compared to $23 \%$ of African Americans and $19 \%$ of Hispanics. People of color are more likely to live in poor neighborhoods where access to basic necessities and medical care is restricted ${ }^{[48]}$.

Long-time, it has been proven that there is a causal link between poverty and the spread of infectious diseases. In poor neighborhoods, the number of hospitalizations related to influenza is almost double that observed in affluent neighborhoods. This is also the case for paediatric hospitalizations due to secondary bacterial pneumonia. The same goes for tuberculosis, which is very common in poor neighborhoods. These trends are not all explained by the fact that these areas are more populated.

Tuberculosis is particularly linked to the socioeconomic status of individuals ${ }^{[49]}$. Already in the early twentieth century, when the United States was faced with a generalized epidemic of tuberculosis, African-Americans, immigrants and residents of disadvantaged neighborhoods were the most affected because they did not have access to medical care ${ }^{[49]}$.

(Q2): Why does the mortality rate differ from country to country?

Perhaps, because of the health choice or different calculation methods by country.

(Q3): Why, until now, Africa and China seem to be the least infected with this pandemic?

The mortality rate is underestimated compared to the number of people affected in some African countries and in China.

In China, some people believe that reports on the number of people who have died from this disease have been reduced. Others claim that in China everything is being done not to show reality. The Communist Party especially does not want the discontented Chinese to speak out, and does everything to silence them ${ }^{[50]}$.

(Q4): Why is the death rate low in Germany, compared to other European countries such as; France, Belgium, Italy, and England?

Because, Germany did a lot of testing very early; mortality in other countries is overstated; moreover, Germany has more places in intensive care.

(Q5): Is the coronavirus more dangerous than the flu, SARS or Ebola?

Coronavirus has a lower mortality rate than SARS (9.6\%); it has a lower mortality rate than Ebola (50\%); nevertheless, it is a little more contagious than the flu.

(Q6) Are people with blood type $\mathrm{O}$ better immunized against coronavirus?

About twenty scientists from several Chinese universities, hospitals or institutes have published the results of their work, the aim of which was to make a link between a person's blood group and their ability to resist against a risk of infection with Covid- $19^{[51]}$.

In this study, Chinese researchers affiliated with the 
University of Shenzhen, indicate that they studied 2,100 people infected with the virus (coming from three hospitals in Wuhan and Shenzhen). Among the cases observed, $10 \%$ had died. They were then compared to nearly 3,700 Wuhan residents who were uninfected ${ }^{[51]}$. They then compared the proportion of people in each blood group (A, $\mathrm{B}, \mathrm{AB}$ and $\mathrm{O}$ ) among samples of the population and patients with Covid-19. Among the 3694 "lambda" people on whom the study was based, the researchers noted a distribution of approximately $32 \%$ of blood group A; $25 \%$ of $\mathrm{B} ; 9 \%$ of $\mathrm{AB}$ and $34 \%$ of $\mathrm{O}$. Among the 1775 patients tested positive for Covid-19 at Wuhan Jinyintan hospital, this distribution was $38 \%$ of blood group A, $26 \%$ of B, $10 \%$ of $\mathrm{AB}$ and $26 \%$ of $\mathrm{O}$. under base of these analysis, they have conclude that there are $33 \%$ less risk of being contaminated by coronavirus if you are of blood group $\mathrm{O}^{[51]}$.

\section{(Q7): When will Coronavirus end?}

According to a study conducted by Princeton University and published in the journal Science, SARS-CoV-2 will not be neutralized by summer warming. In a university statement, Rachel Baker, co-author of the study, said, "We anticipate that warmer, wetter climates will not slow the virus in the initial stages of the pandemic." According to the researcher, the virus "will spread quickly, whatever the weather." It is specified that in the absence of a vaccine or of control measures, the coronavirus will therefore gradually contaminate a larger part of the population. It is only after leaving the pandemic phase that Coivd-19 could become seasonal.

\section{(Q8): How long is an infected person contagious?}

In early March, the very serious American scientific journal "Lancet" (https://www.thelancet.com/coronaviru s), published a study on the contagiousness of Covid19 , establishing that it had a very high and very long contagiousness. This work was carried out by Chinese doctors who followed for several weeks, in December and January, 191 Covid-19 patients in two hospitals in Wuhan, China. They found that after clinical recovery, almost a third of the patients continued to excrete the virus. Doctors have found in the patients seen that the duration of viral shedding varies from 8 to 37 days after the onset of the first symptoms.

\section{(Q9): Is it possible to contract Covid-19 twice?}

People infected with this virus develop antibodies that allow them to avoid further infection. But the duration of this immunity can be more or less long. Meanwhile, reports of clinically recovered Covid-19 patients developing symptoms of the disease have been reported in Japan and China. Indeed, the special cases of infected patients, clinically cured and who develop symptoms again, should be screened again. But a priori, they do not develop it a second time: it may be due to another classic seasonal virus, or it may be a consequence of a severe form of coronavirus, which can subsequently cause pulmonary super infection.

\section{Conclusion}

All studies making projections on the future are uncertain because no one can accurately predict the future (example: no one to predict the disease of Coronavirus, Ebola, SARS, Spanish flu, etc.). However, we can base ourselves on certain current phenomena to predict the near or far future with degrees of uncertainty not very high as asserted by certain authors. Therefore, under basic of all these results, we can conclude that, although, Coronavirus either an invisible enemy, it constitutes the majority of the case a warning for humanity. Until now, there are had several pandemics and epidemics in the past (Black plague, 250M of deaths; Smallpox, 300M, etc.). It is likely to have the same situation in the future, except if humans change totally of behaviour.

\section{References}

[1] UC Davis Magazine, Summer 2006: Epidemics on the Horizon. Accessed May28, 2020.

http://magazinearchive.ucdavis.edu.

[2] Accessed May 28, 2020.

https://www.scmp.com/news/china/society/article/307499

1/coronavirus-chinas-first-confirmed-covid-19-case-traced -back

[3] Huang C, Wang Y, Li X, et al. Clinical features of patients infected with 2019 novel coronavirus in Wuhan, China. Lancet, 2020, 395(10223): 497-506. https://doi.org/10.1016/S0140-6736(20)30183-5

[4] World Health Organization (WHO), 2020. Archived from the original on 14 May 2020. Accessed 14 May 2020.

[5] European Centre for Disease Prevention and Control. Accessed on April 30, 2020.

https://www.ecdc.europa.eu/en/coronavirus

[6] Household cleaners and disinfectants can cause health problems when not used properly. Centers for Disease Control and Prevention (CDC). (Accessed on May 30, 2020).

https://twitter.com/cdcgov/status/1253742258853199872? lang=en

[7] New coronavirus stable for hours on surfaces. National Institutes of Health. (Accessed on May 30, 2020). https://www.sciencedaily.com/releases/2020/03/20031715 0116.htm

[8] van Doremalen N, Bushmaker T, Morris DH, et al. Aerosol and Surface Stability of SARS-CoV-2 as Compared with SARS-CoV-1. The New England Journal of Medicine, 2020, 382(16): 1564-1567. https://doi.org/10.1056/NEJMc2004973 
[9] Novel Coronavirus - Information for Clinicians. Australian Government Dept of Health. (Accessed on May 30, 2020). https://ww2.health.wa.gov.au/Articles/A_E/Coronavirus

[10] Interim Clinical Guidance for Management of Patients with Confirmed Coronavirus Disease (COVID-19). Centers for Disease Control and Prevention (CDC). Retrieved 19 May 2020.

[11] Yang X, Yu Y, Xu J, et al. Clinical course and outcomes of critically ill patients with SARS-CoV-2 pneumonia in Wuhan, China: a single-centered, retrospective, observational study. The Lancet. Respiratory Medicine, 2020, 8(5): 475-481. https://doi.org/10.1016/S2213-2600(20)30079-5

[12] Chen N, Zhou M, Dong X, et al. "Epidemiological and clinical characteristics of 99 cases of 2019 novel coronavirus pneumonia in Wuhan, China: a descriptive study. Lancet, 2020, 395(10223): 507-513. https://doi.org/10.1016/S0140-6736(20)30211-7

[13] Huang C, Wang Y, Li X, et al. Clinical features of patients infected with 2019 novel coronavirus in Wuhan, China. Lancet, 2020, 395(10223): 497-506. https://doi.org/10.1016/S0140-6736(20)30183-5

[14] Lai CC, Shih TP, Ko WC, et al. Severe acute respiratory syndrome coronavirus 2 (SARS-CoV-2) and coronavirus disease-2019 (COVID-19): The epidemic and the challenges. International Journal of Antimicrobial Agents, 2020, 55(3): 105924. https://doi.org/10.1016/j.ijantimicag.2020.105924

[15] Report of the WHO-China Joint Mission on Coronavirus Disease 2019. 16-24 February 2020.

[16] Zheng YY, Ma YT, Zhang JY, et al. COVID-19 and the cardiovascular system. Nature Reviews Cardiology, 2020, 17(5): 259-260. https://doi.org/10.1038/s41569-020-0360-5

[17] Xydakis MS, Dehgani-Mobaraki P, Holbrook EH, et al. Smell and taste dysfunction in patients with COVID-19. Lancet, 2020, 20: 1015-1016. https://doi.org/10.1016/S1473-3099(20)30293-0

[18] Rapid Expert Consultation Update on SARS-CoV-2 Surface Stability and Incubation for the COVID-19 Pandemic. The National Academies Press. 27 March 2020. doi:10.17226/25763. ISBN 978-0-309-67610-6. https://doi.org/10.17226/25763

[19] Interim Guidance: Public Health Management of cases and contacts associated with novel coronavirus (COVID-19) in the community. BC Centre for Disease Control. Retrieved 20 May 2020.

[20] Ferguson NM, Laydon D, Nedjati-Gilani G, et al. Report 9: Impact of non-pharmaceutical interventions (NPIs) to reduce COVID19 mortality and healthcare demand (Report). Imperial College London. Retrieved 25 March 2020. https://doi.org/10.25561/77482

[21] Lai CC, Liu YH, Wang CY, et al. Asymptomatic carrier state, acute respiratory disease, and pneumonia due to severe acute respiratory syndrome coronavirus 2 (SARS-CoV2): Facts and myths. Journal of Microbiology, Immunology, and Infection, 2020, 53(3): 404-412. https://doi.org/10.1016/j.jmii.2020.02.012
[22] Furukawa NW, Brooks JT and Sobel J. Evidence Supporting Transmission of Severe Acute Respiratory Syndrome Coronavirus 2 While Presymptomatic or Asymptomatic. Emerging Infectious Diseases, 2020, 26(7): e1-e6. https://doi.org/10.3201/eid2607.201595

[23] Huang C, Wang Y, Li X, et al. Clinical features of patients infected with 2019 novel coronavirus in Wuhan, China. Lancet, 2020, 395(10223): 497-506. https://doi.org/10.1016/S0140-6736(20)30183-5

[24] Byass P. Eco-epidemiological assessment of the COVID-19 epidemic in China, January-February 2020. Global Health Action, 2020, 13(1): 1760490. https://doi.org/10.1101/2020.03.29.20046565

[25] Zhou F, Yu T, Du R, et al. Clinical course and risk factors for mortality of adult inpatients with COVID-19 in Wuhan, China: a retrospective cohort study. Lancet, 2020, 395(10223): 1054-1062. https://doi.org/10.1016/S0140-6736(20)30566-3

[26] Izaguirre-Torres D and Siche R. Covid-19 disease will cause a global catastrophe in terms of mental health: A hypothesis. Medical Hypotheses, 2020, 143: 109846. https://doi.org/10.1016/j.mehy.2020.109846

[27] Lansiaux E, Pébaÿ PP, Picard JL, et al. COVID-19: betathalassemia subjects immunised? Medical Hypotheses, 2020, 142: 109827. https://doi.org/10.20944/preprints202004.0349.v1

[28] Rowan NJ and Laffey JG. Challenges and solutions for addressing critical shortage of supply chain for personal and protective equipment (PPE) arising from Coronavirus disease (COVID19) pandemic - Case study from the Republic of Ireland. Science of the Total Environment, 2020, 725: 138532. https://doi.org/10.1016/j.scitotenv.2020.138532

[29] Liu J, Zhou J, Yao J, et al. Impact of meteorological factors on the COVID-19 transmission: A multicity study in China. Science of the Total Environment, 2020, 726: 138513. https://doi.org/10.1016/j.scitotenv.2020.138513

[30] Vecchio S, Ramella R, Drago A, et al. COVID19 pandemic and people with opioid use disorder: innovation to reduce risk. Psychiatry Research, 2020, 289: 113047. https://doi.org/10.1016/j.psychres.2020.113047

[31] Merindol N, Pépin G, Marchand C, et al. SARS-CoV-2 detection by direct rRT-PCR without RNA extraction. Journal of Clinical Virology, 2020, 128: 104423. https://doi.org/10.1016/j.jcv.2020.104423

[32] Moghanibashi-Mansourieh A. Assessing the anxiety level of Iranian general population during COVID-19 outbreak. Asian Journal of Psychiatry, 2020, 51: 102076. https://doi.org/10.1016/j.ajp.2020.102076

[33] Peters MC, Sajuthi S, Deford P, et al. COVID-19 Related Genes in Sputum Cells in Asthma: Relationship to Demographic Features and Corticosteroids. American Journal of Respiratory and Critical Care Medicine, 2020, 202(1): 1-34. https://doi.org/10.1164/rccm.202003-08210C

[34] Dai WC, Zhang HW, Yu J, et al. CT Imaging and Differential Diagnosis of COVID-19. Canadian Association of Radiologists Journal, 2020: 846537120913033. https://doi.org/10.1177/0846537120913033 
[35] Mahmoudi M. Emerging Biomolecular Testing to Assess the Risk of Mortality fromCOVID-19 Infection. Molecularpharmaceutics, 2020: 0c00371.

https://doi.org/10.1021/acs.molpharmaceut.0c00371

[36] Chen N, Zhou M, Dong X, et al. Epidemiological and clinical characteristics of 99 cases of 2019 novel coronavirus pneumonia in Wuhan, China: a descriptive study. Lancet, 2020, 395(10223): 507-513. https://doi.org/10.1016/S0140-6736(20)30211-7

[37] Kleine-Weber H, Schroeder S, Kruger N, et al. Polymorphisms in dipeptidyl peptidase4 reduce host cell entry of Middle East respiratory syndrome coronavirus. Emerg Microbes Infect, 2020, 9: 155-168. https://doi.org/10.1080/22221751.2020.1713705

[38] Raj VS, Mou H, Smits SL, et al. Dipeptidyl peptidase 4 is a functional receptor for the emerging human coronavirusEMC. Nature, 2013, 495: 251-254. https://doi.org/10.1038/nature12005

[39] Papi M and Caracciolo G. Principal component analysis of personalized biomolecular corona data for early disease detection. Nano Today, 2018, 21: 14-17. https://doi.org/10.1016/j.nantod.2018.03.001

[40] Palchetti S, Caputo D, Digiacomo L, et al. Protein corona fingerprints of liposomes: New opportunities for targeted drug delivery and early detection in pancreatic cancer. Pharmaceutics, 2019, 11(1): 31 https://doi.org/10.3390/pharmaceutics11010031

[41] Monde L. accessed on June 02, 2020. https://www.lemonde.fr/planete/article/2020/04/09/corona virus-dans-le-monde-les-pays-europeens-exhortes-a-surm onter-leurs-divisions-face-aux-consequences-economique s_6036058_3244.html

[42] L'OBS. accessed on June 2, 2020. https://www.nouvelobs.com/coronavirus-de-wuhan/20200 409.OBS27303/le-coronavirus-provoque-les-pires-conse quences-economiques-depuis-1929-previent-le-fmi.html
[43] International Labor Organization. Accessed on June 2, 2020.

https://www.ilo.org/global/lang-en/index.htm

[44] Myllyvirta L. Analysis: Coronavirus has temporarily reduced China's $\mathrm{CO} 2$ emissions by a quarter. (Accessed on June2, 2020).

[45] McMahon J. Study: Coronavirus Lockdown Likely Saved 77,000 Lives In China Just By Reducing Pollution. (Accessed on June20, 2020).

[46] Sauter MB. 10 years later, these 28 US cities never recovered from the Great Recession, 2018. https://eu.usatoday.com/story/money/economy/2018/10/12 /cities-never-recovered-great-recession/38094325

[47] Hadler JL, Yousey-Hindes K, Pérez A, et al. InfluenzaRelated Hospitalizations and Poverty Levels - United States, 2010-2012. Mmwr Morbidity \& Mortality Weekly Report, 2016, 65: 101-105. https://doi.org/10.15585/mmwr.mm6505a1

[48] Blow CM. Social Distancing Is a Privilege 2020. accessed on June $10,2020$.

https://www.nytimes.com/2020/04/05/opinion/coronavirus -social-distancing.html

[49] Noppert GA and Clarke P. The Modern Profile of Tuberculosis: Developing the TB Social Survey to understand contemporary social patterns in tuberculosis. Public Health Nurs, 2018, 35: 48-55. https://doi.org/10.1111/phn.12372

[50] Youtube. Accessed on June 06, 2020. https://www.youtube.com/watch? $\mathrm{v}=\mathrm{BdKKssKdaN0}$

[51] Zhao J, Yang Y, Huang H, et al. Relationship between the ABO Blood Group and the COVID-19 Susceptibility. medRxiv, 2020 . https://doi.org/10.1101/2020.03.11.20031096 